\title{
О ВЗАИМОДЕИСТВИИ ПИРИТА С АЗОТНОЙ КИСЛОТОЙ
}

\author{
(Представил М. Вейдерма)
}

Разложение фосфатного сырья азотной кислотой обычно сопровождается выделением оксидов азота. Источниками последних являются, с одной стороны, сама техническая азотная кислота ['], с другой - взаимодействующие с азотной кислотой закисные формы железа, содержащиеся в минеральной части, а также органическое вещество [ $\left.{ }^{2}\right]$. Потери азотной кислоты наиболее существенны при переработке пиритсодержащих фосфоритов, например фосфоритов прибрежной зоны Прибалтийского бассейна $\left[{ }^{3-5}\right]$, при этом они пропорциональны содержанию сульфидной серы в сырье [6]. Установлено, что величина потерь зависит также от технологических параметров процесса разложения, в особенности от концентрации азотной кислоты [3]. В настоящей работе поставлена цель уточнить химизм взаимодействия пирита с азотной кислотой в зависимости от концентрации последней. Литературных данных по этому вопросу нами не найдено.

Исходный образец природного пирита содержал 98,0\% $\mathrm{FeS}_{2}, 0,25 \%$ $\mathrm{SiO}_{2}, 0,2 \%$ сульфатной серы и $0,85 \%$ нерастворимого остатка. Пирит измельчали до размера частиц 0,15 мм. Навеску пирита в количестве 0,37 г (3,0 ммоля) разлагали в стеклянной колбе в атмосфере гелия при $70{ }^{\circ} \mathrm{C}$ азотной кислотой в концентрации $60,45,35,25$ и $15 \%$. Количество $100 \%$-ной азотной кислоты всегда составляло 4,1 г за исключением одного опыта (№ 1 в табл. 1), когда ее было 8,2 г. При всех концентрациях кислоты пирит полностью разлагался за 30 мин, при $15 \%$-ной же концентрации для этого потребовалось до 60 мин. Окраска выделяющихся газов менялась от темно-бурой $\left(\mathrm{NO}_{2}\right)$ до бесцветной $\left(\mathrm{NO}, \mathrm{N}_{2} \mathrm{O}\right)$ с переходом от более высоких концентраций кислоты к более низким. Было обнаружено и образование серы, особенно при концентрациях кислоты 25 и $15 \%$. Отходящие из реакционной колбы газы пропускали через три абсорбера с $5 \%$-ным раствором пероксида водорода. По окончании опыта определяли по разности исходной и конечной концентраций $\mathrm{H}_{2} \mathrm{O}_{2}$ в абсорберах его расход на окисление оксидов азота, а титрованием раствором $\mathrm{NaOH}$ - количество образовавшейся азотной кислоты. Последнее определяли также по разности исходного и конечного количества азотной кислоты в реакционной колбе.

При взаимодействии пирита с азотной кислотой (в случае окисления сульфидной серы до сульфатной) могут протекать следующие реакции:

$$
\begin{gathered}
\mathrm{FeS}_{2}+15 \mathrm{NO}_{3}^{-}+14 \mathrm{H}^{+}=\mathrm{Fe}^{3+}+2 \mathrm{SO}_{4}^{2-}+7 \mathrm{H}_{2} \mathrm{O}+15 \mathrm{NO}_{2}, \\
\mathrm{FeS}_{2}+5 \mathrm{NO}_{3}^{-}+4 \mathrm{H}^{+}=\mathrm{Fe}^{3+}+2 \mathrm{SO}_{4}^{2-}+2 \mathrm{H}_{2} \mathrm{O}+5 \mathrm{NO}, \\
8 \mathrm{FeS}_{2}+30 \mathrm{NO}_{3}^{-}+22 \mathrm{H}^{+}=8 \mathrm{Fe}^{3+}+16 \mathrm{SO}_{4}^{2-}+11 \mathrm{H}_{2} \mathrm{O}+15 \mathrm{~N}_{2} \mathrm{O} \\
2 \mathrm{FeS}_{2}+6 \mathrm{NO}_{3}^{-}+4 \mathrm{H}^{+}=2 \mathrm{Fe}^{3+}+4 \mathrm{SO}_{4}^{2-}+2 \mathrm{H}_{2} \mathrm{O}+3 \mathrm{~N}_{2}, \\
8 \mathrm{FeS}_{2}+15 \mathrm{NO}_{3}^{-}+22 \mathrm{H}^{+}+19 \mathrm{H}_{2} \mathrm{O}=8 \mathrm{Fe}^{3+}+16 \mathrm{SO}_{4}^{2-}+15 \mathrm{NH}_{4}^{+} .
\end{gathered}
$$


Реакция (5) не протекала из-за отсутствия аммониевого иона в продуктах реакции. Как видно, расход азотной кислоты на окисление пирита изменяется в большом диапазоне в зависимости от глубины ее восстановления - от 15 молей при образовании $\mathrm{NO}_{2}$ до 3 молей при образовании $\mathrm{N}_{2}$ на 1 моль $\mathrm{FeS}_{2}$. Аналогично изменяется и количество выделяющихся газов. При окислении сульфидной серы до элементарной расход азотной кислоты еще больше уменьшается: при образовании $\mathrm{NO}$ он составляет всего 1 моль на 1 моль $\mathrm{FeS}_{2}$

$$
\mathrm{FeS}_{2}+\mathrm{NO}_{3}^{-}+4 \mathrm{H}^{+}=2 \mathrm{~S}+\mathrm{Fe}^{3+}+2 \mathrm{H}_{2} \mathrm{O}+\mathrm{NO} .
$$

При пропускании газовых продуктов реакции через раствор пероксида водорода оксиды азота окисляются по следующим реакциям:

$$
\begin{gathered}
2 \mathrm{NO}_{2}+\mathrm{H}_{2} \mathrm{O}_{2}=2 \mathrm{HNO}_{3}, \\
2 \mathrm{NO}+3 \mathrm{H}_{2} \mathrm{O}_{2}=2 \mathrm{HNO}_{3}+2 \mathrm{H}_{2} \mathrm{O}, \\
\mathrm{N}_{2} \mathrm{O}+4 \mathrm{H}_{2} \mathrm{O}_{2}=2 \mathrm{HNO}_{3}+3 \mathrm{H}_{2} \mathrm{O} .
\end{gathered}
$$

Из сравнения реакций (1)-(3) с реакциями (7)-(9) соответственно следует, что для оксидов азота, выделяющихся при реагировании 1 моля $\mathrm{FeS}_{2}$, расходуется одинаковое количество пероксида водорода - 7,5 моля. Исключение составляет реакция (4), в ходе которой азот, проходя абсорберы, не реагирует с пероксидом водорода.

По расходу пероксида водорода и гидроксида натрия (на нейтрализацию образовавшейся $\mathrm{HNO}_{3}$ ) мы рассчитали количественный состав выделяющихся оксидов азота. С другой стороны, состав газа рассчитали по расходу азотной кислоты на окисление пирита. Расчет корректен лишь в случае двухкомпонентного состава оксидов азота.

Таблица 1

\begin{tabular}{|c|c|c|c|c|c|c|}
\hline \multirow{2}{*}{ 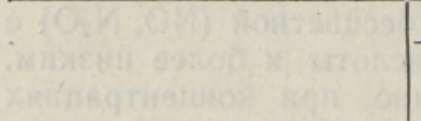 } & \multicolumn{6}{|c|}{ Номер опыта } \\
\hline & 1 & 2 & 3 & 4 & 5 & 6 \\
\hline $\begin{array}{l}\text { Концентрация } \mathrm{HNO}_{3}, \% \\
\text { в начале опыта } \\
\text { в конце опыта }\end{array}$ & $\begin{array}{l}60 \\
49\end{array}$ & $\begin{array}{l}60 \\
32\end{array}$ & $\begin{array}{l}45 \\
26\end{array}$ & $\begin{array}{l}35 \\
23\end{array}$ & $\begin{array}{l}25 \\
17\end{array}$ & $\begin{array}{r}15 \\
9\end{array}$ \\
\hline Расход $\mathrm{H}_{2} \mathrm{O}_{2}$, ммоль & 22,0 & 22,3 & 22,2 & 21,2 & 17,6 & 17,0 \\
\hline $\begin{array}{l}\text { Количество прореагировав- } \\
\text { шего пирита, \% }\end{array}$ & 97,8 & 99,0 & 98,7 & 94,2 & 78,2 & 75,6 \\
\hline Расход $\mathrm{NaOH}$, ммоль & 21,00 & 18,52 & 16,42 & 13,02 & 10,75 & 9,15 \\
\hline $\begin{array}{l}\text { Расчетный состав выделяю- } \\
\text { щихся оксндов азота, \% } \\
\mathrm{NO}_{2} \\
\mathrm{NO}^{2} \\
\mathrm{~N}_{2} \mathrm{O}\end{array}$ & $\begin{array}{l}45 \\
55\end{array}$ & $\begin{array}{l}30 \\
70\end{array}$ & $\begin{array}{l}15 \\
85\end{array}$ & $\begin{array}{l}85 \\
15\end{array}$ & $\begin{array}{l}(84) \\
(16)\end{array}$ & $\begin{array}{l}(44) \\
(56)\end{array}$ \\
\hline $\begin{array}{l}\text { Количество выделяющихся } \\
\text { оксидов азота на } 1 \text { моль } \\
\mathrm{FeS}_{2} \text { мольь }\end{array}$ & 7,2 & 6,2 & 5,5 & 4,6 & 3,6 & 3,1 \\
\hline $\begin{array}{l}\text { Потери } \mathrm{HNO}_{3} \text { (в пересчете на } \\
100 \% \text {-ную) на } 1 \mathrm{r} \mathrm{FeS} 2, \mathrm{r}\end{array}$ & 3,8 & 3,3 & 2,9 & 2,4 & 1,9 & 1,6 \\
\hline
\end{tabular}

Результаты изучения взаимодействия пирита с азотной кислотой в атмосфере гелия Условия экспериментов: темп. $70^{\circ} \mathrm{C}$, время опыта 30 мин, количество $\mathrm{FeS}_{2} 3,0$ ммоля $(0,37 \mathrm{r})$ 
Как показывают расчетные данные (табл. 1), при $35 \%$-ной концентрации кислоты и выше пирит реагирует практически полностью - в пределах 94-99\%. При более низких концентрациях - только на 75 $78 \%$. В связи с этим можно предположить, что в последнем случае выделяется молекулярный азот, который не реагирует с пероксидом водорода. Однако определением суммарного количества азота в виде оксидов, выделяющихся и реагирующих с $\mathrm{H}_{2} \mathrm{O}_{2}$ либо растворяющихся в реакционной массе, получается, что и при низких концентрациях коэффициент разложения пирита составляет около $95 \%$.

Кроме того, при низких концентрациях $\mathrm{HNO}_{3}$ образовывалась элементарная сера, при этом меньше выделялось оксидов азота (6). Определением количества выделенной серы найдено, что содержание газов уменьшается при этом на $5 \%$. Очевидно, часть газов растворяется в кислоте, к примеру $\mathrm{N}_{2} \mathrm{O}$ хорошо растворяется в воде.

Представленный состав выделяющихся газов, приблизительный и рассчитанный, корректен лишь в случае двухкомпонентного состава оксидов азота. Действительно, в третьем опыте можно предполагать выделение $\mathrm{N}_{2} \mathrm{O}$, а в четвертом - $\mathrm{NO}_{2}$, хотя бы в незначительном количестве. Результаты, полученные в пятом и шестом опытах с применением $\mathrm{HNO}_{3}$ $25 \%$-ной концентрации и ниже, поставлены в скобки, поскольку в расчетах не учтено образование серы, а также возможность растворения выделяющихся оксидов азота в оставшейся реакционной массе (табл. 1).

Как видно из этих данных; расход азотной кислоты значительно зависит от концентрации применяемой $\mathrm{HNO}_{3}$. Например, расход $15 \%$-ной азотной кислоты примерно в 2 раза меньше, чем расход $60 \%$-ной.

Для сравнения приведем опытные данные, которые получены при разложении эстонских фосфоритов азотной кислотой $30 \%$-ной концентрации при температуре $75^{\circ} \mathrm{C}$ (табл. 2) $\left[{ }^{4}\right]$.

Таблица 2

Результаты взаимодействия фосфорита с азотной кислотой

\begin{tabular}{|c|c|c|c|c|}
\hline \multirow[b]{2}{*}{ Фосфорит } & \multirow[b]{2}{*}{$\begin{array}{c}\text { Содержание } \\
\text { пиритной серы } \\
\mathrm{SO}_{3}, \%\end{array}$} & \multirow[b]{2}{*}{$\begin{array}{l}\text { Содержание } \\
\mathrm{FeS}_{2} \text { в I кr } \\
\text { фосфорита, r }\end{array}$} & \multicolumn{2}{|c|}{ Потери $100 \%$-ной $\mathrm{HNO}_{3}, \mathrm{r}$} \\
\hline & & & $\begin{array}{c}\text { на } 1 \text { кг } \\
\text { фосфорорита }\end{array}$ & $\begin{array}{l}\text { на } 1 \text { r } \\
\mathrm{FeS}_{2}\end{array}$ \\
\hline
\end{tabular}

$\begin{array}{lllll}\text { Тоолсеский } & 1,86 & 13,9 & 31,6 & 2,27 \\ \text { Маардуский } & 4,97 & 37,3 & 74,0 & 1,98\end{array}$

В случае реагирования чистого пирита с кислотой той же концентрации потери $\mathrm{HNO}_{3}$ с выделяющимися газами были равными - 2,2 г на $1 \Gamma \mathrm{FeS}_{2}$, что близко к значениям потерь $\mathrm{HNO}_{3}$ в табл. 2.

Проведенное исследование показало, что потери азотной кислоты при разложении эстонских фосфоритов зависят главным образом от содержания в них пирита. Химизм взаимодействия азотной кислоты с пиритом, а также количество и состав выделяющихся газов различны при различной концентрации кислоты.

\section{ЛИТЕРА ТУ РА}

1. Гольдинов А. Л., Абрамов О. Б., Шищканов А. П. Об источниках образования окислов азота при разложении апатитового концентрата азотной кнслотой. - Ж. прнкл. химин, 1977, L, № 6, 6.

2. Вольфкович С. Н., Соколовский A. А. Комплексные удобрения на основе азотнокислотного разложения фосфатов. - Успехи химни, 1974, XLIII, № 3, 564. 
3. Аасамяэ Э. Э., Вейдерма М. А., Кудрявцева Е. Н. Исследование азотнокислотного разложения тоолсеского фосфорита. - Тр. Таллин. лолитехн. ин-та. Неор: химия и технология I, 1980, № 479, 3-11.

4. Аасамяэ Э., Вейдерма М. Влияние добавки карбамида на азотнокислотно-сульфат ную переработку природных фосфатов. - Изв. АН ЭССР. Хим., 1983, 32, № 1, $1-7$.

5. Аасамяэ Э., Вейдерма М. Азотнокислотно-сульфатная переработка фосфоритов Раквереского месторождения. - Изв. АН ЭССР. Хим., 1984, 34, № 2, 73-78.

6. Кудрявщева Е. Н., Аасамяэ Э. Э., Вейдерма М. А. Влияние состава фосфатного сырья на его азотнокислотную переработку. - Тр. Таллин. политехн. ин-та. Неорг. химия и технология II, 1983, № 542, 1!-23.

Таллинский политехнический институт

Поступила в редакцию $25 /$ II 1988

\section{E. ARUMEEL, J. KUDRJAVTSEVA}

\section{PURIIDI REAGEERIMINE LÄMMASTIKHAPPEGA}

On uuritud loodusliku püriidi reageerimist erineva kontsentratsiooniga lämmastikhappega $70^{\circ} \mathrm{C}$ juures. Reaktsioonil eraldunud lämmastikoksiidid määrati kvalitatiivselt ja kvantitatiivselt. Saadud tulemustest selgus, et happe kontsentratsiooni vähenemisel tekivad madalama oksüdatsiooniastmega lämmastikoksiidid ja väheneb reaktsiooniks vajalik lämmastikhappe hulk.

\section{E. ARUMEEL, Ye. KUDRJAVTSEVA}

\section{THE REACTION OF PYRITE WITH NITRIC ACID}

An analysis of the reactions of natural pyrite with nitric acid of different concentration at $70^{\circ} \mathrm{C}$ has been studied. In these processes separated nitric oxides were qualitatively and quantitatively investigated. The results show that a more dilute nitric acid gives nitric oxides with a lower oxidation degree and the necessary quantity of nitric acid for reaction diminishes. 